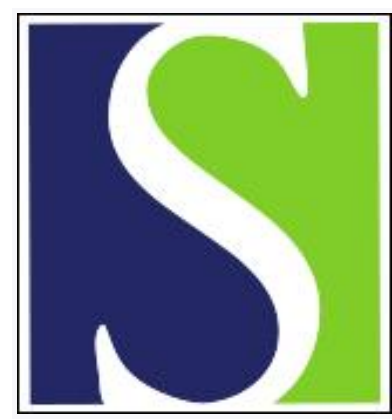

Scand J Work Environ Health 2006;32(4):310-317

https://doi.org/10.5271/sjweh.1015

Issue date: 31 Aug 2006

Objective neuropsychological test performance of professional divers reporting a subjective complaint of "forgetfulness or loss of concentration"

by Taylor CL, Macdiarmid JI, Ross JAS, Osman LM, Watt SJ, Adie W, Crawford JR, Lawson A

Affiliation: Department of Environmental \& Occupational Medicine, University of Aberdeen, Liberty Safe Work Research Centre, Foresterhill Road, Aberdeen, AB25 2ZP, United Kingdom. j.a.ross@abdn.ac.uk

Key terms: diving; forgetfulness; loss of concentration; memory; neuropsychological test; professional diver; subjective complaint; test performance

This article in PubMed: www.ncbi.nlm.nih.gov/pubmed/16932829 


\title{
Objective neuropsychological test performance of professional divers reporting a subjective complaint of "forgetfulness or loss of concentration"
}

\author{
by Claire L Taylor, PhD, ${ }^{1}$ Jennifer I Macdiarmid, PhD, ${ }^{1}$ John AS Ross, PhD, ${ }^{1}$ Liesl M Osman, PhD, ${ }^{2}$ \\ Stephen J Watt, MBBS, ${ }^{1}$ Wendy Adie, MPhil, ${ }^{3}$ John R Crawford, PhD, ${ }^{3}$ Andrew Lawson, PhD ${ }^{4}$
}

Taylor CL, Macdiarmid JI, Ross JAS, Osman LM, Watt SJ, Adie W, Crawford JR, Lawson A. Objective neuropsychological test performance of professional divers reporting a subjective complaint of "forgetfulness or loss of concentration". Scand J Work Environ Health 2006;32(4):310-317.

\begin{abstract}
Objective This study attempted to determine whether the higher prevalence of reported "forgetfulness or loss of concentration" among professional divers can be confirmed using objective neuropsychological tests. Secondary aims were to qualify the functional nature of the complaints and to ascertain whether reduced performance was linked to diving history.

Methods In a case-control study, the neuropsychological test performance of divers complaining of moderate or severe "forgetfulness or loss of concentration" was compared with two age-matched control groups reporting no or slight "forgetfulness or loss of concentration" ("nonforgetful" divers and "nonforgetful" nondivers). The group differences were analyzed using a multivariate analysis of co-variance, followed by canonical discriminant function analysis. Altogether 102 divers with a complaint, 100 nonforgetful divers, and 100 nonforgetful nondivers completed the study.

Results The overall neuropsychological performance differed significantly between the groups [Pillai's trace: $\mathrm{F}(24,484)=2.04, \mathrm{P}=0.003]$. Verbal memory (Logical Memory and the California Verbal Learning Test), current intelligence (Wechsler Abbreviated Scale of Intelligence), and sustained attention (rapid visual processing) were poorer among the divers with a complaint than among the nonforgetful divers or the nonforgetful nondivers. The tests of memory, but not those of executive function, differentiated the divers with complaints from the two control groups. Mixed gas bounce diving and surface oxygen decompression diving, but not other techniques, were negatively associated with memory performance.

Conclusions A cognitive complaint of divers was confirmed using objective tests of neuropsychological performance. Memory, rather than executive function, was affected at the group level, but only to a mild degree. The relationships between diving experience and neuropsychological test performance were small and only seen with diving techniques used in the offshore oil and gas industry.
\end{abstract}

Key terms diving; memory; neuropsychological test.

Any impact of diving on the central nervous system and the subsequent possible neuropsychological effect on divers has been the subject of continued interest in the diving industry. Decompression illness is an obvious concern with its potential to cause neurological damage $(1,2)$. It is, however, possible for the diver to make a complete recovery from decompression illness with no residual injury $(3,4)$. Nevertheless, divers do experience physiological stress, short of frank disease, which includes the presence of microbubbles in the venous return to the heart with a potential for systemic and cere- bral embolus through an intracardiac $(5,6)$ or intrapulmonary $(7,8)$ shunt. In addition, several post-mortem studies among divers have identified neuroanatomical abnormalities in the absence of a history of decompression illness (9-11).

Both subjective cognitive complaints and objective neuropsychological test performance have been studied among divers. A higher prevalence of cognitive complaints has been reported by certain groups of divers when compared with nondiving controls (12-14). These complaints are typically described as problems with

1 Department of Environmental \& Occupational Medicine, University of Aberdeen, Aberdeen, United Kingdom.

2 Department of Medicine \& Therapeutics, University of Aberdeen, Aberdeen, United Kingdom.

3 School of Psychology, University of Aberdeen, Aberdeen, United Kingdom.

4 Arnold School of Public Health, University of South Carolina, South Carolina, United States.

Reprint requests to: Dr JAS Ross, Department of Environmental \& Occupational Medicine, University of Aberdeen, Liberty Safe Work Research Centre, Foresterhill Road, Aberdeen, AB25 2ZP, United Kingdom. [E-mail: j.a.ross@abdn.ac.uk] 
memory or concentration, but they have not been quantified in terms of objective neuropsychological performance. Objective quantification of these complaints is an important question to address since the reliability of any subjective complaint can be questioned. It is speculated that divers may be inclined to over-report this particular complaint due to a heightened awareness of the risks associated with diving, publicized within the diving sector and during diver training.

Previous studies of neuropsychological test performance have reported conflicting results among professional divers, some finding indications of a mild neuropsychological deficit (15-18) and others finding no effects. These studies have, however, not uniformly allowed for the effects of age, education, and premorbid IQ (intelligence quotent) on test performance.

A previous health status questionnaire study recruited 1540 professional divers and a comparison group of 1035 age-matched nondiving offshore workers in the oil and gas industry (14). From the reported symptoms in the questionnaire the most pronounced finding was that divers were three times more likely to report moderate or severe "forgetfulness or loss of concentration" than the non-diving control group ( $18 \%$ versus $6 \%, \mathrm{P}<0.001)$. The primary aim of our present study was therefore to investigate whether this higher prevalence of subjective "forgetfulness or loss of concentration" could be confirmed using formal neuropsychological testing and to quantify and qualify the nature of the symptom. A secondary aim was to relate the magnitude of any effect identified with diving experience both in terms of the number and type of dives performed and diving induced disease.

\section{Study population and methods}

\section{Study population}

All of the participants were men aged between 28 and 67 years. Divers had to have gained a professional diving certificate (registered with the Health and Safety Executive, United Kingdom) before 1991. A comparison group of age-matched nondivers was recruited through Liberty Occupational Health Ltd, United Kingdom. These participants were offshore workers in the oil and gas industry who had undergone a medical examination assessing fitness to work offshore between 1990 and 1992 and who had never dived. These criteria ensured that both the divers and nondivers had worked in their industry at least 10 years prior to the study, which would allow time for symptoms relating to their occupation to become manifest. No minimum or maximum time was set for the duration of the career, and it was not necessary for the participants to be working in either profession at the time of the study.
One case and two control groups were recruited from an age-stratified sample of 2575 participants involved in a prior questionnaire study after those who reported a head injury were excluded. Recruitment was based on a self-reported complaint of "forgetfulness or loss of concentration". The severity of the complaint was rated on a 4-point scale from "not at all", "slightly", "moderately" to "extremely". Cases were divers who reported suffering moderately (82\%) or extremely (18\%) from "forgetfulness or loss of concentration" (referred to as "forgetful divers"). The first control group comprised divers who reported to suffer not at all $(55 \%)$ or slightly $(45 \%)$ from "forgetfulness or loss of concentration""nonforgetful divers". The second control group comprised nondiving offshore workers who reported to suffer not at all $(77 \%)$ or slightly $(23 \%)$ from "forgetfulness or loss of concentration"- "nonforgetful nondivers". The number of eligible nondivers, from the questionnaire study, with a moderate or extreme complaint was too few $(\mathrm{N}=46)$ to allow relevant sampling for our present study. Eligible participants were randomly selected from the stratified groups of 201 forgetful divers, 997 nonforgetful divers, and 825 nonforgetful nondivers until at least 100 participants in each of the three groups had completed the study. One hundred and two forgetful divers, 100 nonforgetful divers, and 100 nonforgetful nondivers completed the study.

\section{Exclusion criteria}

People were excluded if English was not their first language $(\mathrm{N}=7)$ or if they had been diagnosed with dyslexia $(\mathrm{N}=8)$ or if there was a further history of head injury. During a medical examination, seven participants reported a head injury with a loss of consciousness of $\geq 1$ hour, and another five did not know the duration of loss of consciousness following a head injury. None of these participants reported a head injury in the questionnaire survey. Excluding these participants gave a final sample of 94 forgetful divers, 89 nonforgetful divers, and 92 nonforgetful nondivers for the analyses.

\section{Study population characteristics}

A lifestyle questionnaire assessed smoking habits, alcohol consumption, and education. Smoking was defined in pack-years, alcohol consumption was expressed as the average number of units consumed per week, and education as the number of years in formal education. The characteristics of the case-control groups were similar (table 1). Forgetful divers had spent fewer years in education than either nonforgetful divers or nonforgetful nondivers, but the premorbid IQ did not differ between the groups. From the National Adult Reading Test (NART), the Wechsler Adult Intelligence Scale-Revised (WAIS$\mathrm{R})$ score was calculated using a standard regression 
Table 1. Characteristics of the case and control groups. $(95 \% \mathrm{Cl}=95 \%$ confidence interval, $\mathrm{IQ}=$ intelligence quotient, WAIS-R $=$ Wechsler Abbreviated Scale of Intelligence)

\begin{tabular}{|c|c|c|c|c|c|c|c|c|c|c|c|c|}
\hline \multirow[t]{3}{*}{ Group } & \multirow{2}{*}{\multicolumn{2}{|c|}{ Age }} & \multirow{2}{*}{\multicolumn{2}{|c|}{$\begin{array}{l}\text { Current \& ex- } \\
\text { smokers }^{a}\end{array}$}} & \multirow{2}{*}{$\begin{array}{l}\text { Alcohol } \\
\text { (units per } \\
\text { week) }\end{array}$} & \multirow[t]{2}{*}{$\begin{array}{l}\text { Education } \\
\text { (years) }\end{array}$} & \multirow{2}{*}{$\begin{array}{c}\text { Pre-morbid } \\
I Q \\
\text { (WAIS-R }^{b}\end{array}$} & \multirow{2}{*}{\multicolumn{2}{|c|}{$\begin{array}{l}\text { Employed The Hospital } \\
\text { at the time- } \\
\text { of study Depression } \\
(\%) \quad \text { score }\end{array}$}} & \multicolumn{3}{|c|}{ Anxiety and Depression Scale } \\
\hline & & & & & & & & & & $\begin{array}{l}\text { Clinical } \\
\text { depression } \\
\text { (score } \\
>10)\end{array}$ & $\begin{array}{c}\text { Anxiety } \\
\text { score } \\
\end{array}$ & $\begin{array}{l}\text { Clinic- } \\
\text { al an- } \\
\text { xiety } \\
\text { (score }\end{array}$ \\
\hline & Mean & $95 \% \mathrm{Cl}$ & Mean & $95 \% \mathrm{Cl}$ & Mean $95 \% \mathrm{Cl}$ & Mean $95 \% \mathrm{Cl}$ & Mean $95 \% \mathrm{Cl}$ & & Mean $95 \% \mathrm{Cl}$ & & Mean $95 \% \mathrm{Cl}$ & $>10$ \\
\hline $\begin{array}{l}\text { Forgetful } \\
\text { divers }(\mathrm{N}=94)\end{array}$ & 46.2 & $44.7-47.7$ & 19.1 & $13.2-25.0$ & $14.911 .7-18.1$ & $12.712 .1-13.2$ & 2 107 105-109 & 983 & $4.7 \quad 4.0-5.4$ & 6 & $7.1 \quad 6.2-7.9$ & $9 \quad 18$ \\
\hline $\begin{array}{l}\text { Nonforgetful } \\
\text { divers }(N=89)\end{array}$ & 47.3 & $45.7-48.9$ & 15.5 & $10.4-20.6$ & $15.412 .3-18.6$ & $13.812 .9-14.6$ & 109 107-111 & 193 & $3.93 .3-4.5$ & 3 & $6.45 .8-7.1$ & 9 \\
\hline $\begin{array}{l}\text { Nonforgetful } \\
\text { nondivers } \\
\text { (N=92) }\end{array}$ & 45.8 & $44.3-47.3$ & 19.0 & $15.0-22.9$ & $12.610 .1-15.1$ & $14.113 .4-14.7$ & $108106-110$ & $0 \quad 91$ & $3.7 \quad 3.1-4.3$ & 1 & $5.9 \quad 5.2-6.7$ & $7 \quad 13$ \\
\hline P-value & & .39 & & .18 & 0.37 & 0.01 & 0.27 & 0.06 & 0.07 & 0.19 & 0.11 & 0.28 \\
\hline
\end{tabular}

a Pack-years for smokers; $52 \%$ of forgetful divers, $42 \%$ of nonforgetful divers, and $49 \%$ of nonforgetful nondivers (P-value 0.16 ).

b The standardized population mean score was 100 .

equation (21), and it was used as a measure of the premorbid IQ. The premorbid IQ was included as a covariate in the analyses. The Hospital Anxiety and Depression Scale (HADS) (22) was completed. A score of 10 or more for either of the parameters defined clinical depression or anxiety. The prevalence of the participants classified as clinically depressed or anxious in this sample was consistent with prevalence estimates for a large sample of the general adult population in the United Kingdom (23).

\section{Neuropsychological assessments}

The Logical Memory test (LM), from the Wechsler Memory Scale III (24), and the California Verbal Learn-

Table 2. Diving experience of forgetful and nonforgetful divers. $(95 \% \mathrm{Cl}=95 \%$ confidence interval, $\mathrm{DCl}=$ decompression illness, $\mathrm{IQR}=$ interquartile range)

\begin{tabular}{lcc}
\hline & $\begin{array}{c}\text { Forgetful } \\
\text { divers } \\
(\mathrm{N}=94) \\
(\%)^{\mathrm{a}}\end{array}$ & $\begin{array}{c}\text { Nonforgetful } \\
\text { divers } \\
(\mathrm{N}=89) \\
(\%)^{\mathrm{b}}\end{array}$ \\
\cline { 2 - 3 } & & \\
Dive techniques used & 87 & 97 \\
$\quad$ Scuba & 86 & 81 \\
Surface demand & 78 & 52 \\
Surface oxygen decompression & 50 & 33 \\
Mixed gas bounce & 53 & 34 \\
Saturation & & \\
Diving accidents & 35 & 18 \\
$\quad$ Pain only DCl & 22 & 5 \\
Neurological DCI & 36 & 14 \\
Contaminated breathing gas & 26 & 10 \\
Underwater explosion & 13 & 5 \\
Loss of consciousness under & & \\
pressure & 26 & 9 \\
Drilling mud burns & & \\
\hline a Total dives: median 1600 (IQR1014-2522); years dived: mean 18 \\
(95\% Cl 17-19). \\
botal dives: median 1033 (IQR 476-2500); years dived: mean 17 \\
(95\% Cl 15-19).
\end{tabular}

ing Test-II (CVLT) (25) measured immediate and delayed memory. A higher score on these tests indicates better performance. The Cambridge Neuropsychological Test Automated Battery (CANTAB) (Cambridge Cognition, Cambridge, UK), a computerized test battery, assessed performance of memory, attention, and executive function. From the CANTAB, the five-choice reaction time (5CRT), rapid visual process task (RVP), spatial recognition memory (SRM), stockings of Cambridge (SOC), and spatial working memory (SWM) were used. Current IQ, measured using the Wechsler Abbreviated Scale of Intelligence (WASI) (26), gave an estimate of global intellectual function (full score) and two subcomponents of current intelligence [matrix reasoning (fluid intelligence) and vocabulary (crystallized intelligence)].

\section{Diving experience}

A detailed professional diving history was taken by a specialist in diving medicine in an interview. The interview included estimates of the number of air-nitrox dives (scuba, surface demand, and surface oxygen decompression diving) and mixed gas dives (mixed gas bounce and saturation diving), details of the industry in which the divers had worked (offshore, inshore and coastal, police, scientific, media, military, recreational instructor, shellfish), and the number of diving accidents (neurological or pain only decompression illness, exposure to contaminated gas, underwater explosion, loss of consciousness under pressure and drilling mud burn).

The duration of the diving career was similar for both the forgetful divers and the nonforgetful divers, but forgetful divers had performed more dives during this time (table 2). A higher proportion of forgetful divers had used surface oxygen decompression, mixed gas bounce, and saturation diving techniques, and they were more likely to have dived in the offshore industry than 
nonforgetful divers were ( $71 \%$ versus $54 \%$ ). Nonforgetful divers were more likely to have been police $(35 \%$ versus $16 \%)$, scientific (19\% versus $8 \%$ ) or media (19\% versus $4 \%$ ) divers. A higher proportion of forgetful divers had dived to a depth of more than 50 meters on air-nitrox. At the time of the study, the same proportion of forgetful divers and nonforgetful divers had ended their professional diving career (51\% versus 52\%). Diving-related accidents were more common among the forgetful divers than among the nonforgetful divers, as was the prevalence of drilling mud burn.

\section{Test procedure}

The neuropsychological test battery was part of a series of medical and physiological assessments. The neuropsychological tests were always presented in the same order (NART, CANTAB, CVLT, LM, WASI) using standardized instructions. The test assessors were blind to the participant group. The participants were asked to refrain from drinking alcohol for 24 hours prior to the study.

\section{Statistical analysis}

The differences in the participant characteristics between the groups (table 1) were tested using an analysis of variance (ANOVA) for continuous data and chisquared tests for categorical data. Since many of the neuropsychological tests were highly correlated, the overall neuropsychological performance between the groups was compared using a multivariate analysis of co-variance (MANCOVA). The MANCOVA included 12 measures from the neuropsychological tests and the current IQ (WASI). Data were assessed for normality using a Kolmogorov-Smirnov test. Where data departed from normality, a transformation was used. Prior to the analyses, the 5CRT score was log-transformed, and the SRM and RVP scores were arcsine-transformed as these are proportional data. These are standard transformation techniques recommended by Cambridge Cognition (Cambridge, UK) for these CANTAB generated datasets. Age, alcohol consumption, smoking (packyears), education, premorbid IQ, and depression and anxiety scores (HADS) were included in the analysis as confounders. Pairwise comparisons from the subsequent ANCOVA results were conducted to illustrate differences between the groups for individual tests. The MANCOVA was then followed by a canonical discriminant analysis. This analysis was used to determine relationships between the neuropsychological variables used. Two functions were produced from this analysis (canonical correlations), and Wilks' lambda was used to test their significance in relation to the case-control groups. An individual discriminant score for each of the two functions was produced for each participant. Partial correlations were performed that adjusted for age and premorbid IQ between discriminant scores and measures of diving experience. All of the analyses were conducted using SPSS (version 12.1, SPSS Inc, Chicago, IL USA).

\section{Neuropsychological abnormalities}

Abnormality in test performance was defined as a score of 1.65 or more standard deviations below the normative population mean (5th percentile of the general population). Normative data for the tests involved were taken from the relevant test manuals [eg, LM (24), CVLT (25)]. This cut-off point was chosen since scores falling below this level are considered statistically significantly different from the mean $(\mathrm{P}<0.05)$ and can be taken as an indication that the person has an impairment on the task in question (27).

This study went ahead after a favorable opinion regarding the study had been obtained from the Grampian Research Ethics Committee.

\section{Results}

\section{Objective neuropsychological tests}

The neuropsychological test performance differed significantly between the groups [Pillai's trace: $\mathrm{F}(24,484)=2.04, \mathrm{P}=0.003]$, $9 \%$ of the variance in neuropsychological performance being explained by group membership $\left(\eta_{\mathrm{p}}{ }^{2}=0.09\right)$ (table 3 ). The canonical discriminant analysis identified two functions with canonical correlations of 0.36 and 0.26 (table 4). The first function was found to distinguish the forgetful divers from both the nonforgetful divers and nonforgetful nondivers $(\mathrm{P}<0.001)$. The tests most highly correlated with this function had a strong memory component (LM, CVLT) and included the verbal component of the current IQ measure (WASI-vocab). We therefore referred to it as the memory function (table 4). The mean discriminant score for the memory function was -0.48 [95\% confidence interval (95\% CI) $-0.70--0.27), 0.46$ (95\% CI $0.65-0.28)$, and 0.05 (95\% CI $-0.18-0.27$ ) for the forgetful divers, nonforgetful divers, and nonforgetful nondivers, respectively. A negative score indicated poorer performance. The second function correlated with tests associated with planning (SOC), executive memory (SWM), and sustained attention (RVP) and was referred to as the executive function. This function did not, however, discriminate significantly between the case and control groups $(\mathrm{P}=0.09)$. The mean executive function scores for forgetful divers $(-0.16,95 \%$ CI $-0.35-0.04)$ and nonforgetful divers $(-0.21,95 \%$ CI $-0.40--0.02)$ 
Table 3. Objective neuropsychological test results for each group [mean and 95\% confidence intervals (95\% CI)]. (FD = "forgetful" divers, NFD = "nonforgetful" divers, NFND = "nonforgetful" nondivers)

\begin{tabular}{|c|c|c|c|c|c|c|c|c|c|c|c|}
\hline & \multicolumn{2}{|c|}{ FD } & \multicolumn{2}{|c|}{ NFD } & \multicolumn{2}{|c|}{ NFND } & \multirow{2}{*}{$\begin{array}{c}\text { F-test } \\
\text { P-value }^{\text {a }}\end{array}$} & \multirow{2}{*}{$\begin{array}{c}\text { Variance } \\
\text { explained } \\
\left(\eta_{p}^{2}\right)\end{array}$} & \multicolumn{3}{|c|}{ Pairwise comparisons } \\
\hline & Mean & $95 \% \mathrm{Cl}$ & Mean & $95 \% \mathrm{Cl}$ & Mean & $95 \% \mathrm{Cl}$ & & & & FD & NFD \\
\hline \multicolumn{12}{|l|}{ Logical Memory test } \\
\hline Immediate recall & 40.6 & $38.9-42.3$ & 45.5 & $43.6-47.4$ & 44.9 & $42.9-47.0$ & 0.007 & 0.04 & $\begin{array}{l}\text { NFD } \\
\text { NDNF }\end{array}$ & $\begin{array}{l}P<0.05 \\
P<0.05\end{array}$ & \\
\hline Delayed recall & 24.0 & $22.5-25.4$ & 29.1 & $27.7-30.5$ & 27.8 & $26.4-29.3$ & $<0.001$ & 0.08 & $\begin{array}{l}\text { NFD } \\
\text { NDNF }\end{array}$ & $\begin{array}{l}P<0.01 \\
P<0.01\end{array}$ & \\
\hline \multicolumn{12}{|c|}{ California verbal learning test-II } \\
\hline Immediate recall & 48.1 & $46.1-50.1$ & 52.5 & $50.4-54.6$ & 50.7 & $48.3-53.1$ & 0.03 & 0.03 & $\begin{array}{l}\text { NFD } \\
\text { NDNF }\end{array}$ & $P<0.05$ & \\
\hline Delayed recall & 10.4 & $9.8-11.1$ & 12.2 & $11.6-12.9$ & 11.1 & $10.4-11.9$ & 0.002 & 0.05 & $\begin{array}{l}\text { NFD } \\
\text { NDNF }\end{array}$ & $P<0.01$ & \\
\hline \multicolumn{12}{|l|}{ CANTAB } \\
\hline $\begin{array}{l}\text { Rapid visual process } \\
\text { (a prime) }\end{array}$ & 0.90 & $0.89-0.91$ & 0.92 & $0.91-0.93$ & 0.92 & $0.91-.093$ & 0.02 & 0.03 & $\begin{array}{l}\text { NFD } \\
\text { NDNF }\end{array}$ & $\begin{array}{l}P<0.05 \\
P<0.05\end{array}$ & $P<0.05$ \\
\hline $\begin{array}{l}\text { Spatial recognition } \\
\text { memory (\% correct) }\end{array}$ & 81.1 & $79.0-83.4$ & 84.1 & $82.1-86.1$ & 82.7 & $80.3-85.1$ & 0.09 & 0.02 & $\begin{array}{l}\text { NFD } \\
\text { NDNF }\end{array}$ & & \\
\hline $\begin{array}{l}\text { Stockings of Cambridge } \\
\text { (minimum moves) }\end{array}$ & 8.9 & $8.5-9.3$ & 9.0 & $8.7-9.4$ & 9.2 & $8.8-9.6$ & 0.74 & 0.002 & $\begin{array}{l}\text { NFD } \\
\text { NDNF }\end{array}$ & & \\
\hline $\begin{array}{l}\text { Spatial working memory } \\
\text { (between search errors) }\end{array}$ & 23.3 & $20.3-26.4$ & 22.7 & $19.1-26.3$ & 20.3 & $17.1-23.5$ & 0.67 & 0.003 & $\begin{array}{l}\text { NFD } \\
\text { NDNF }\end{array}$ & & \\
\hline Five choice reaction time & 346 & $335-357$ & 333 & $323-343$ & 341 & $330-351$ & 0.27 & 0.01 & $\begin{array}{l}\text { NFD } \\
\text { NDNF }\end{array}$ & & \\
\hline \multicolumn{12}{|c|}{ Wechsler Abbreviated Scale of Intelligence } \\
\hline Vocabulary & 55.8 & $54.1-57.4$ & 59.4 & $58.2-60.7$ & 57.2 & $55.2-59.1$ & 0.048 & 0.006 & $\begin{array}{l}\text { NFD } \\
\text { NDNF }\end{array}$ & & \\
\hline Matrix reasoning & 57.1 & $55.8-58.5$ & 58.8 & $57.8-60.0$ & 58.3 & $56.7-60.0$ & 0.47 & 0.02 & $\begin{array}{l}\text { NFD } \\
\text { NDNF }\end{array}$ & & \\
\hline Full score & 111.4 & 109.2-113.6 & 116.1 & $114.5-117.6$ & 113.9 & $111.2-116.5$ & 0.08 & 0.02 & $\begin{array}{l}\text { NFD } \\
\text { NDNF }\end{array}$ & & \\
\hline
\end{tabular}

a Adjusted for age, premorbid intelligence quotient, alcohol consumption, smoking, education, and depression and anxiety, and for multiple comparisons.

were lower than for the nonforgetful nondivers $(0.37$, 95\% CI 0.14-0.61).

\section{Neuropsychological abnormalities}

The prevalence of abnormality according to the neuropsychological tests was lower than the expected population level of 5\% in both the case and control groups, with the exception of the RVP test, for which the prevalence of forgetful divers was $8 \%$.

\section{Diving history and memory function}

The partial correlations related to the measures of diving experience and the memory function score are shown in table 5. After adjustment for age and premorbid IQ, negative relationships between memory function and the number of surface oxygen decompression dives and mixed gas bounce dives were found. These relationships remained unaltered when the analysis was repeated excluding divers with a history of neurological decompression illness. The memory function score was not significantly lower for the divers with a history of neurological decompression illness (mean -0.42,
95\% CI -0.87-0.04) than for those never having suffered from neurological decompression illness $(0.04,95 \%$ CI $-0.13-0.21)$, but the confidence intervals identified did not exclude an effect. The memory function score was not related to any of the other diving accidents identified.

\section{Discussion}

This study has confirmed that divers with a subjective cognitive complaint of forgetfulness or loss of concentration have an observable deficit in neuropsychological performance measured using objective neuropsychological testing when compared with those with no complaint. Moreover, the subjective complaint of divers was particularly associated with poorer performance on tests of memory rather than with executive function. The group association of spatial working memory with tests of executive function in this study may seem anomalous in this context. Working memory is, however, regarded as a test of executive function since it requires the explicit use of strategy to constantly update memory 
Table 4. Correlation coefficients between the neuropsychological test scores and the canonical function scores. The correlations in bold type indicate the tests that relate most significantly to each of the two functions.

\begin{tabular}{|c|c|c|}
\hline & $\begin{array}{l}\text { Function } 1 \\
\text { (memory) }\end{array}$ & $\begin{array}{c}\text { Function } 2 \\
\text { (executive } \\
\text { function) }\end{array}$ \\
\hline \multicolumn{3}{|l|}{ Logical Memory test } \\
\hline Immediate recall & 0.58 & 0.34 \\
\hline Delayed recall & 0.83 & 0.23 \\
\hline \multicolumn{3}{|l|}{ California Verbal Learning Test-II } \\
\hline Immediate recall & 0.46 & 0.05 \\
\hline Delayed recall & 0.58 & -0.12 \\
\hline $\begin{array}{l}\text { Spatial recognition memory } \\
\text { (\% correct) }\end{array}$ & 0.32 & 0.01 \\
\hline \multicolumn{3}{|c|}{ Wechsler Abbreviated Scale of Intelligence } \\
\hline Vocabulary & 0.48 & -0.19 \\
\hline Matrix & 0.29 & 0.04 \\
\hline Full score & 0.48 & -0.06 \\
\hline \multicolumn{3}{|l|}{ CANTAB } \\
\hline Five choice reaction time & -0.27 & 0.04 \\
\hline Rapid visual process task (a prime) & 0.40 & 0.47 \\
\hline $\begin{array}{l}\text { Spatial working memory (between } \\
\text { search errors) }\end{array}$ & -0.004 & -0.37 \\
\hline $\begin{array}{l}\text { Stockings of Cambridge } \\
\text { (minimum moves) }\end{array}$ & 0.10 & 0.25 \\
\hline Canonical correlation & $0.36^{a}$ & $0.26^{b}$ \\
\hline
\end{tabular}

a Wilks' $\Lambda=0.81, \chi^{2}(24)=54.8 P<0.001$.

' Wilks' $\Lambda=0.94, \chi^{2}(11)=17.6 \mathrm{P}=0.09$.

Table 5. Partial correlations between memory function score and diving history.

\begin{tabular}{|c|c|c|c|c|c|}
\hline & \multirow[t]{2}{*}{$\mathrm{N}$} & \multicolumn{4}{|c|}{$\begin{array}{l}\text { Partial correlations }(r) \text { with } \\
\text { memory function score }\end{array}$} \\
\hline & & $\begin{array}{l}\text { Un- } \\
\text { adjusted }\end{array}$ & $\begin{array}{c}\mathrm{P}- \\
\text { value }\end{array}$ & Adjusted $^{\mathrm{a}}$ & P-value \\
\hline Total number of dives & 165 & -0.18 & 0.02 & -0.11 & 0.16 \\
\hline Years worked as a diver & 165 & -0.21 & 0.007 & -0.12 & 0.11 \\
\hline \multicolumn{6}{|l|}{ Dive techniques (N) } \\
\hline Scuba & 165 & -0.03 & 0.97 & 0.02 & 0.77 \\
\hline Surface demand & 165 & -0.16 & 0.04 & -0.05 & 0.50 \\
\hline $\begin{array}{l}\text { Surface oxygen } \\
\text { decompression }\end{array}$ & 165 & -0.23 & 0.003 & -0.20 & 0.009 \\
\hline Mixed gas bounce & 165 & -0.23 & 0.003 & -0.24 & 0.002 \\
\hline $\begin{array}{l}\text { Saturation (number } \\
\text { of days) }\end{array}$ & 165 & -0.08 & 0.32 & -0.06 & 0.47 \\
\hline
\end{tabular}

${ }^{a}$ Adjusted for age and premorbid intelligence quotient.

traces. The functional specificity of the objective impairment in memory, but not executive function, suggests disruption in hippocampal brain circuitry, rather than disruption in the frontal lobe, particularly since the working memory test showed no impairment in divers with a subjective complaint. Previous research suggests that patients with damage to the frontal lobe suffer both amnesic and dysexecutive symptoms. For example, the amnesic deficit seen following frontal lobe damage includes impairment on word list free recall tests (28) and is hypothesized to originate from impaired strategic organization of encoding and retrieval processes (29). Thus a group with impaired frontal function would be expected to perform poorly on both tests of free recall and working memory tests in which there is a strong strategic component. In contrast, a group with impaired memory per se (but not executive memory) would be expected to show the pattern of deficit observed in our group of divers with a complaint.

When the deficit in neuropsychological performance in the forgetful divers was quantified, it was clear that it was mild. In addition, the incidence of frank clinical neuropsychological abnormality was no higher than that found in the general population. This was not unexpected, since, in terms of age-related cognitive decline, the study population was relatively young, the majority was in full-time employment, and they had a relatively high level of education. However, the tests (LM and CVLT) that separated forgetful divers from the control groups are highly sensitive to mild subclinical brain injury (30, 31). The CVLT, for example, has been shown to be sensitive enough to predict the occurrence of Alzheimer's dementia in nonclinical elderly persons who are genetically at risk of developing the disease (32). Therefore, although they are mild, the differences identified for forgetful divers are clinically relevant.

Since the details of occupational exposure were obtained retrospectively in this study, causality cannot be inferred from our findings. Nevertheless, there were differences in diving history between the forgetful divers and nonforgetful divers. Previous work has shown a negative relationship between diving experience (ie, number of dives and years worked as a diver) and cognitive performance when adjusted for age $(12,33)$. However, these studies did not take into account baseline cognitive ability, thus making interpretation difficult. While there is no real substitute for longitudinal studies, it is possible to make adjustments for baseline cognitive ability using estimates of premorbid IQ (34). In this study, after adjusting for premorbid IQ, we found that the relationship between the duration of diving career or the total number of dives and objective memory performance was no longer observed. We did, however, find associations with the increased use of particular diving techniques and memory performance. Mixed gas bounce diving and surface oxygen decompression diving were associated with poorer memory performance. Both of these techniques can create high decompression stress and are associated with the presence of gas bubbles in the venous return from tissues with a potential for decompression illness (35). However, in our study, decompression illness did not explain any relationship with these diving techniques. Nevertheless, a possible explanation of the relationship, in the absence of clinical decompression illness, could be that a degree of bubble embolism to the cerebral circulation, while 
not causing frank decompression illness, may produce subclinical cerebral tissue damage. If this were the case, a clearer relationship between memory score and decompression illness would be expected. Both of these techniques are exclusive to the offshore oil industry, and such relationships may reflect an influence of working in this industry, quite independently of any particular effect of diving.

The offshore oil industry is associated with other risks, such as exposure to toxins (36), some of which have the potential to cause brain damage. Petrochemicals, solvents, and hydrogen sulfide have all been associated with deficits in neuropsychological function (37, 38). Divers can be exposed to these agents by diving in contaminated water, where the toxins can be absorbed through the skin or inhaled in accidentally contaminated breathing gas, either in the diver's gas supply or from a contaminated atmosphere in the diving bell or pressure chamber habitat $(36,39)$. In relation to possible dermatological exposure and toxin uptake, drilling mud burns were observed to occur more frequently among forgetful divers. These burns are dermatitic ulcers caused by defatting of the skin by contact with solvents in the mud (40). They are a marker of toxin penetration of the diving suit worn and indicate exposure of these divers to any other toxins in the water. Divers can also be exposed to other neurological toxins, such as carbon monoxide, through accidental contamination of their breathing gas.

Not all studies have observed a reduction in neuropsychological test performance among divers. This lack of a reduction, however, may be attributable to a relatively small effect occurring only in a limited proportion of the study group. These previous studies of general populations of divers would not be expected to have the power to detect such an effect. In this study, by screening the population prior to testing, we were able to identify the underlying nature of cognitive complaint in the study group of professional divers.

The current study has both strengths and weaknesses. The participants were randomly selected from agestratified groups. The sample size was large and the case and control groups had similar lifestyles. Also, unlike most previous studies of neuropsychological performance conducting a battery of tests, we carried out a single analysis to include all the tests demonstrating an overall difference in neuropsychological performance rather than performing individual analyses for each test. Furthermore, adjustments were made for potential important confounding variables in all of the analyses.

A possible limitation of the study was the lack of a nondiver group with a subjective cognitive complaint. Such a limitation might have indicated different functional correlates with a complaint among nondivers or even differences in the severity of effect. However, this possibility did not affect the aim of this study, which was to determine whether the higher prevalence of a reported cognitive complaint among professional divers could be confirmed using objective neuropsychological tests.

In summary, this study has shown that the higher prevalence of the subjective complaint of "forgetfulness or loss of concentration" among professional divers was associated with lower objective neuropsychological performance, specifically memory rather than executive function. The effect on these divers was mild, but its implications for any long-term prognosis are unknown. Accordingly, the determination of long-term prognosis requires a follow-up study.

\section{Acknowledgments}

The authors would like to acknowledge the work of the ELTHI diving project secretaries Anne Henderson and Leanne Dow.

This study was funded by the Health and Safety Executive, United Kingdom.

\section{References}

1. Rozsahegyi I. Late consequences of the neurological forms of decompression sickness. Br J Ind Med. 1959;16:311-7.

2. Vaernes RJ, Eidsvik S. Central nervous dysfunctions after near-miss accidents in diving. Aviat Space Environ Med. 1982;53(8):803-7.

3. Hickish AE, Hickish GW, Harvey J, Francis TJR, Mullee M. Neurobehavioural impairment after neurological decompression illness. Norwich (UK): Health Safety Executive; 2002. Research report 017.

4. Andrews G, Holt P, Edmonds C, Lowry RC, Cistulli P, McKay $\mathrm{B}$, et al. Does non-clinical decompression stress lead to brain damage in abalone divers? Med J Aust. 1986;144:399-401.

5. Wilmshurst P, Bryson P. Relationship between the clinical features of neurological decompression illness and its causes. Clin Sci. 2000;99:65-75.

6. Kerut EK, Norfleet WT, Plotnick GD, Giles TD. Patent foramen ovale: a review of associated conditions and the impact of physiological size. J Am Coll Cardiol. 2001;38(3):613-23.

7. Eldridge MW, Dempsey JA, Haverkamp HC, Lovering AT, Hokanson JS. Exercise-induced intrapulmonary arteriovenous shunting in healthy humans. J Appl Physiol. 2004;97:797805.

8. Stickland MK, Welsh RC, Haykowsky MJ, Petersen SR, Anderson WD, Taylor DA et al. Intra-pulmonary shunt and pulmonary gas exchange during exercise in humans. J Physiol. 2004;15(561.1):321-9.

9. Palmer AC, Calder IM, Yates PO. Cerebral vasculopathy in divers. Neuropathol Appl Neurobiol. 1992;18(2):113-24.

10. Palmer AC, Calder I, Hughes JT. Spinal cord degeneration in divers. Lancet. 1987;8572(2):1365-6. 
11. Morild I, Mork SJ. A neuropathologic study of the ependymoventricular surface in diver brains. Undersea Hyperb Med. 1994;21(1):43-51.

12. Todnem K, Nyland H, Kambestad BK, Aarli JA. Influence of occupational diving upon the nervous system: an epidemiological study. Br J Ind Med. 1990;47:708-14.

13. Shields TG, Cattanach S, Duff PM, Evans SA, Wilcock SE. Investigation into possible contributory factors to decompression sickness in commercial air diving and the long-term neurological consequences. Sheffield (UK), Health Safety Executive; 1996. OTO Report 96953.

14. Macdiarmid JI, Ross JAS, Taylor CL, Watt SJ, Adie W, Osman LM, et al. Co-ordinated investigation into the possible long term health effects of diving at work: the ELTHI Diving Study. Norwich (UK): Health Safety Executive; 2004. Research Report no 230.

15. Peters B H, Levin HS, Kelly P J. Neurologic and psychologic manifestations of decompression illness in divers. Neurology. 1977;27(2):125-7.

16. Vaernes R, Klove H, Ellertsen B. Neuropsychologic effects of saturation diving. Undersea Biomed Res. 1989;16(3):233-51.

17. Tetzlaff K, Friege L, Hutzelmann A, Reuter M, Holl D, Leplow B. Magnetic resonance signal abnormalities and neuropsychological deficits in elderly compressed air divers. Eur Neurol. 1999;42:194-9.

18. Leplow B, Tetzlaff K, Holl D, Zeng L, Reuter M. Spatial orientation in construction divers-are there associations with diving experience? Int Arch Occup Environ Health. 2001;74:189-98.

19. Bast-Pettersen R. Long-term neuropsychological effects in non-saturation construction divers. Aviat Space Environ Med. 1999;70(1):51-7.

20. Cordes P, Keil R, Bartsch T, Tetzlaff K, Reuter M, Hutzelmann A, et al. Neurologic outcome of controlled compressedair diving. Neurology. 2000;55:1743-5.

21. Nelson HE, Willison J. The revised National Adult Reading test: test manual. Windsor (United Kingdom): NFER-Nelson, 1991.

22. Zigmond AS, Snaith RP. The Hospital Anxiety and Depression Scale. Acta Psychiatr Scand. 1983;67:361-70.

23. Crawford JR, Crombie JD, Taylor EP. Normative data for the HADS from a large non-clinical sample. Br J Clin Psychol. 2001;40:429-34.

24. Wechsler D. Wechsler Memory Scale. 3rd ed. San Antonio (TX): The Psychological Corporation; 1997.

25. Delis DC, Kramer JH, Kaplan E, Ober BA. California Verbal Learning Test. 2nd ed. San Antonio (TX): The Psychological Corporation; 2000.

26. Wechsler D. Wechsler Abbreviated Scale of Intelligence. San
Antonio (TX): The Psychological Corporation; 1999.

27. Crawford JR, Garthwaite PH. Evaluation of criteria for classical dissociations in single-case studies by Monte Carlo simulation. Neuropsychol. 2005;19(5):664-78.

28. Daum I, Schugens MM, Spieker S, Poser U, Schoelne PW, Birbaumer N. Memory and skill acquisition in Parkinson's disease and frontal lobe dysfunction. Cortex. 1995;31:41332.

29. Mayes AR, Daum I. How specific are the memory and other cognitive deficits caused by frontal lobe lesions? In: Rabbitt $\mathrm{P}$, editor. Methodology of frontal and executive function. Hove (UK): Psychology Press; 1997. p. 155-76.

30. Guilmette TRD. Sensitivity, specificity, and diagnostic accuracy of three verbal memory measures in the assessment of mild brain injury. Neuropsychology. 1995;9(3):338-44.

31. Baddeley AD. Working memory. Philos Trans R Soc Lond B Biol Sci. 1983;302(1110):311-24.

32. Bondi MW, Monsch AU, Galasko D, Butter N, Salmon DP, Delis DC. Preclinical cognitive markers of dementia of the Alzheimer type. Neuropsychology. 1994;8(3):374-84.

33. Morris PE, Leach J, King J, Rawlins J. Psychological and neurological impairment in professional divers. London (UK): Dept of Energy; 1991. Final Report 2050.

34. Crawford JR, Deary IJ, Starr JM, Whalley LJ. The NART as an index of prior intellectual functioning: a retrospective validity study covering a 66 year interval. Psychol Med. 2001;31:451-8.

35. Nishi RY, Brubakk AO, Eftedal OS. Bubble detection. In: Brubakk AO, Neuman TS, editors. Bennett and Elliott's physiology and medicine of diving. 5th ed. London: Saunders; 2003. p. 501-29.

36. Gardner R. Overview and characteristics of some occupational exposures and health risks on offshore oil and gas installations. Ann Occup Hyg. 2003;47(3):201-10.

37. Morrow LA, Stein L, Bagovich GR, Condray R, Scott A. Neuropsychological assessment, depression, and past exposure to organic solvents. Appl Neuropsychol. 2001;8(2):6573.

38. Nilson LN, Backman L, Sallsten G, Hagberg S, Barregard L. Dose-related cognitive deficits among floor layers with previous heavy exposure to solvents. Arch Environ Health. 2003;58(4):208-17.

39. International Marine Contractors Association. Diving in contaminated waters. London: IMCA; 2004. Report D 021 Rev 1.

40. Ormerod AD, Dwyer CM, Goodfield MJ. Novel causes of contact dermatitis from offshore oil-based drilling muds. Contact Derm. 1998;39(5):262-3.

Received for publication: 14 November 2005 